\title{
Synthesis of Silver Nanoparticles Using Triticum aestivum and Its Effect on Peroxide Catalytic Activity and Toxicology
}

\author{
Shobha Waghmode, ${ }^{1}$ Pooja Chavan, ${ }^{1}$ Vidya Kalyankar, ${ }^{1}$ and Sharada Dagade ${ }^{2}$ \\ ${ }^{1}$ Department of Chemistry, Abasaheb Garware College, Pune 411004, India \\ ${ }^{2}$ Department of Chemistry, Y. M. College, Bharati Vidyapeeth, Pune 411038, India
}

Correspondence should be addressed to Shobha Waghmode; shobhawaghmode@yahoo.co.in

Received 6 May 2013; Revised 10 June 2013; Accepted 11 June 2013

Academic Editor: Hassan Karimi-Maleh

Copyright (c) 2013 Shobha Waghmode et al. This is an open access article distributed under the Creative Commons Attribution License, which permits unrestricted use, distribution, and reproduction in any medium, provided the original work is properly cited.

\begin{abstract}
The synthesis of stable silver nanoparticles using bioreduction method was investigated. Biological synthesis of silver nanoparticles using Triticum aestivum (khapali ghahu) extract was investigated. The effect of a specific variety of plants and how it affects the growth of silver nanoparticles was investigated in our work and it was polydispersed. UV-visible spectroscopy was used to monitor the formation of silver nanoparticles within 15 minutes. The peaks in XRD pattern are in good agreement with those of face-centered-cubic form of metallic silver. Further the IR and TEM shows confirmation of nanocrystalline nature of silver nanoparticles. These nanoparticles dislodged by ultrasonication showed an absorption peak at $430 \mathrm{~nm}$ in UV-visible spectrum corresponding to the Plasmon resonance of silver nanoparticles. UV-visible titration experiments showed evidence that silver nanoparticles facilitate hydrogen peroxide reduction showing excellent catalytic activity at $200 \mu \mathrm{L}$. In this preliminary toxicology study, Earthworm toxicology we checked and is stable up to $1500 \mathrm{ppm}$ concentration. The use of plant extract for silver nanoparticles synthesis offers the benefits of eco-friendliness and amenability for large-scale production.
\end{abstract}

\section{Introduction}

In recent years, noble metal nanoparticles have been the subject of focused research due to their unique optical, electronic, mechanical, magnetic, and chemical properties that are significantly different from those of bulk materials [1]. From different carbon-based nanomaterials, carbon nanotubes can be used to promote electron transfer reactions when used as electrode material [2-6] in electrochemical devices, electrocatalysis, and electroanalysis processes due to their significant mechanical strength, high electrical conductivity, high surface area, good chemical stability, as well as relative chemical inertness in most electrolyte solutions, and a wide operation potential [7-14]. Many other applications of nanoparticles are now known such as sensor in nanosize containing $\mathrm{Mn}$ nanoparticles decorated organo-functionalized nanosized $\mathrm{SiO}_{2}-\mathrm{Al}_{2} \mathrm{O}_{3}$ mixed-oxide support was developed as a new electro catalysis for oxidation of organic compounds such as many important drugs [6].

Preparation of silver nanoparticles has attracted particularly considerable attention due to their diverse properties and uses, like magnetic and optical polarizability, electrical conductivity, catalysis, antimicrobial and antibacterial activities, DNA sequencing, and surface-enhanced Raman scattering (SERS). The synthesis of silver nanoparticles with controlled morphology is important for uncovering their specific properties and for achieving their practical applications [15]. Silver nanoparticles are of current importance because of their easy preparation process and unique optical, electrical, and thermal properties.

Many techniques are used for synthesizing silver nanoparticles, such as chemical reduction of metal salt. The development of toxicity-free metal nanoparticles has become a great challenge in recent times. Various chemical and physical methods have been employed to prepare silver nanoparticles with different sizes and shapes, such as UV irradiation [16], microware irradiation [17], chemical reduction [18], photochemical method [19], electron irradiation [20], and sonoelectrochemical method [21]. However, most of the reported methods involve more than one step, high energy requirement, low material conversions, difficulty in purification, and 
hazardous chemicals [22]. The chemical synthesis of nanoparticles may lead to the presence of some toxic chemical species adsorbed on the surface that may have adverse effects in its application.

The synthesis of nanoparticles by green method can potentially eliminate this problem. Therefore, there is an urgent need to develop a green process of nanoparticle synthesis. Green synthesis methods employing either biological microorganisms or plant extracts have emerged as a simple and alternative to chemical synthesis [23]. Green synthesis provides advancements over chemical methods as it is environment friendly, cost effective, and easily scaled up for large scale synthesis. The synthesis of nanoparticles by using plant extracts can be advantageous over other biological processes because it eliminates the elaborate process of maintaining cell cultures and can be suitably scaled up for large scale production under nonaseptic environments [24].

Silver nanoparticles are well known as one of the most universal antimicrobial substances in the field of biology and medicine due to their strong biocidal effect against microbial species, which have been used for centuries to prevent and treat various diseases, most notably infections [25]. Recently, the development of silver nanoparticles is expanding. They are now used as part of clothing, food containers, wound dressings, ointments, and implant coatings. Some silver nanoparticles' applications have received approval from the US Food and Drug Administration [26]. In the present work, we have proposed a green chemical method for synthesizing Ag nanoparticles using water extract as reducing and capping agents. Triticum aestivum (khapali ghahu) has many applications in Ayurveda as said for diabetes and many other diseases as home remedy. Specifically this variety is grown in western Maharashtra and it has great potential for research. To the best of our knowledge, this study is new and presents a simple methodology to synthesize Ag nanoparticles efficiently at room temperature. With this, to studying toxicology is very important nowadays.

\section{Experimental}

Triticum aestivum (khapali ghahu) species has medicinal importance for diabetes and many other remedies in Ayurveda. The seeds were chosen from Western Maharashtra, that is, from Agriculture College, Pune. We planted these species in our college in pots, and silver nitrate $\left(\mathrm{AgNO}_{3}\right)$ was purchased from Merck, Germany.

\subsection{Preparation of Extract. We brought Triticum aestivum} (khapali ghahu) species from Agriculture College, Pune. We had given treatment for the seeds. First we kept them in sunlight for 10 hours and then we sowed them in organic soil with very little amount of water. We added 10 grams in each pot and after nine days we harvested them for silver nanosynthesis. Aqueous extract was filtered by $0.45 \mu \mathrm{m}$ Millipore membrane filter and followed by $0.2 \mu \mathrm{m}$ Millipore membrane filter.

2.2. Synthesis of Silver Nanoparticles. For synthesis of silver nanoparticles, $100 \mathrm{~mL}$ of $\mathrm{AgNO}_{3}(1 \mathrm{mM})$ was reacted with

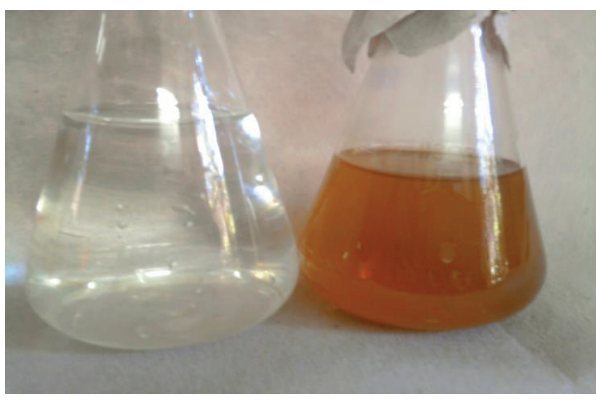

(a)

(b)

Figure 1: Aqueous solution of $10^{-3} \mathrm{M} \mathrm{AgNO}_{3}$ with Triticum aestivum extract (a) before adding extract and (b) after addition extract at 3-5 minutes.

$5 \mathrm{~mL}$ of the extract in Erlenmeyer flask at room temperature. Any colour changes of the solution were observed.

2.3. Characterization. The crystallinity and phases of the Ag nanoparticles were characterized by X-ray diffractometer (XRD-6000, Shimadzu, Japan) with $\mathrm{Cu}_{k \alpha}$ radiation $(\lambda=$ $1.5412 \AA$ ) in the range $10^{\circ}-80^{\circ}$ with $2^{\circ} /$ min scanning rate. The further composition of Ag nanoparticles were characterized by Fourier-Transform Infrared (FTIR, Perkin Elmer, Spectrum BX) spectroscopy in the range $4000-280 \mathrm{~cm}^{-1}$. In addition, the optical property of prepared $\mathrm{Ag}$ nanoparticles was analyzed via UV-visible (UV-Vis, Perkin Elmer, Lambda 35) absorption double beam spectrophotometer with a deuterium and tungsten iodine lamp in the range from 200 to $1100 \mathrm{~nm}$ at room temperature. The transmission electron microscopy (TEM) micrographs were taken for morphological analysis of nanoparticles with a JEOL 3010 field emission electron microscope with an accelerating voltage of $300 \mathrm{kV}$. The samples were analysed by preparing a dilute solution made in distilled water and drop casted on a carbon coated copper grid, followed by drying the sample at ambient conditions before it was attached to the sample holder on the microscope.

\section{Results and Discussion}

After treatment in sunlight and the proper growth in pot, the extract of Triticum aestivum (khapali ghahu) species was used for further synthesis. The process followed was first washing the saplings with distilled water to remove soil and roots. Then after weighing these saplings, we crushed in mixer grinder for paste followed by filtration by muslin cloth. Now the extract is ready for synthesis. Immediately after addition of $5 \mathrm{~mL}$ extract to $100 \mathrm{~mL}$ of $\mathrm{AgNO}_{3}(1 \mathrm{mM})$, we observed the colour change by visual observation in the Erlenmeyer flask which contains $\mathrm{AgNO}_{3}$ solution. The colour of the $\mathrm{AgNO}_{3} /$ Triticum aestivum extract solution changed from colourless to light brown after $5 \mathrm{~min}$ and eventually to dark brown (15 minutes) (Figure 1). This colour change indicates the formation of silver nanoparticles in the solution. Triticum aestivum without $\mathrm{AgNO}_{3}$ did not show any colour changes 


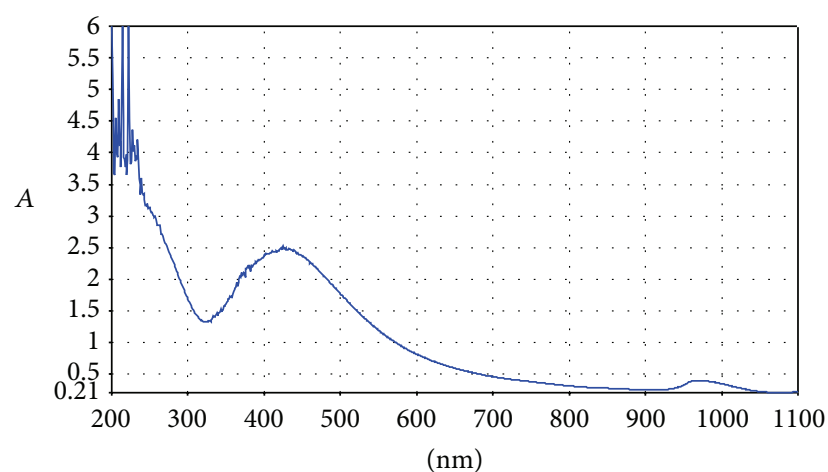

FigURE 2: UV-VIS spectrum of extract and $\mathrm{AgNO}_{3}$ solution $(1 \mathrm{mM})$.

which we have checked with control experiment. Figure 1 shows aqueous solution of $10^{-3} \mathrm{M} \mathrm{AgNO}_{3}$ with Triticum aestivum extract (a) before adding extract and (b) after addition extract at 3-5 minutes.

Figure 2 shows the UV-visible absorption spectrum of the synthesized Ag nanoparticles. Silver nanoparticles have free electrons, which give surface Plasmon resonance (SPR) absorption band, due to the combined vibration of electrons of silver nanoparticles in resonance with light wave. A broad absorption peak was observed at $430 \mathrm{~nm}$, which is a characteristic band for the $\mathrm{Ag}$ [27]. No other peak was observed in the spectrum which confirms that the synthesized products are Ag only.

Figure 3 shows XRD patterns for silver nanoparticles synthesized by Triticum aestivum extract. Five main characteristic diffraction peaks for Ag were observed at $2 \theta=$ $32.8,38.18,46.5,64.7$, and 77.8 which correspond to the main (111), (200), (220), (311), and (222) crystallographic planes of face-centered cubic (fcc) Ag crystals, Figure 2, respectively (JCPDS 00-004-0783). No peaks from any other phase were observed showing that single-phase Ag with cubic structure nanoparticles has been obtained directly [28].

In general, the width of XRD peaks is related to crystallite size. Debye-Scherrer equation was used to determine average crystallite diameter from half width of the diffraction peaks: $D=(k \lambda) /(\beta \cos \theta)$, where $D$ is mean crystallite size of the powder, $\lambda$ is the wavelength of $\mathrm{Cu}_{k \alpha}, \beta$ is the full width at half-maximum, $\theta$ is the Bragg diffraction angle, and $k$ is a constant. The (111) plane was chosen to calculate crystalline size. From Debye-Scherrer equation, the average crystallite size of silver nanoparticles synthesized is found to be $5.42 \mathrm{~nm}$.

Catalytic activity using hydrogen peroxide was done for silver nanoparticles in aqueous solution. Various concentrations were carried to do this titration from $100 \mu \mathrm{L}$ to $1000 \mu \mathrm{L}$ solution from $30 \%$ hydrogen peroxide. It is stable up to $200 \mu \mathrm{L}$ and very responsive to this concentration and silver nanoparticles get oxidised at this concentration. UV-visible titration experiment yielded evidence that silver nanoparticles facilitate hydrogen peroxide reduction showing excellent catalytic activity.

FTIR measurement was carried out to identify the possible biomolecules responsible for capping and reducing agent for the Ag nanoparticles synthesized by tea leaf extract.

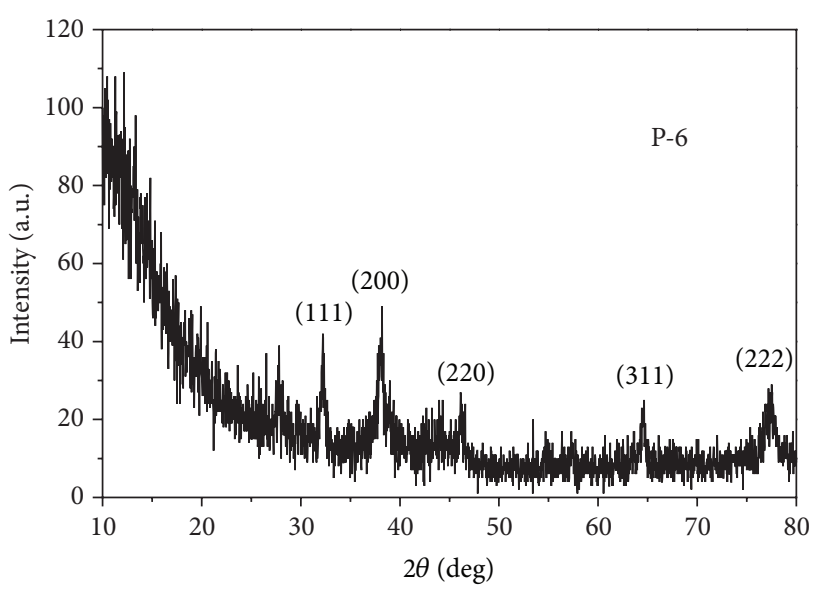

FIGURE 3: XRD pattern of silver nanoparticles.

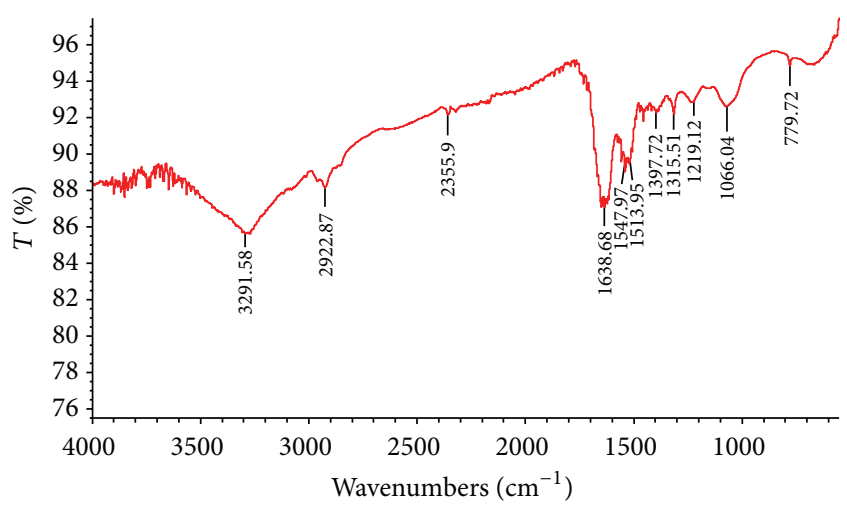

FIGURE 4: FTIR spectrum of silver nanoparticles showing characteristics peak.

Three obvious infrared bands are observed at $3291 \mathrm{~cm}^{-1}$ and $1638 \mathrm{~cm}^{-1}$ (Figure 4). The intense broad band at $3291 \mathrm{~cm}^{-1}$ is due to $\mathrm{N}-\mathrm{H}$ and $\mathrm{O}-\mathrm{H}$ stretching mode in the linkage of the proteins. The medium intense band at $1638 \mathrm{~cm}^{-1}$ arises from the $\mathrm{C}=\mathrm{O}$ stretching mode in amine I group which is commonly found in the protein [29], indicating the presence of proteins as capping agent for silver nanoparticles which increases the stability of the nanoparticles synthesized. On the other hand, the intense and broad peak at $402 \mathrm{~cm}^{-1}$ corresponded to the Ag metal.

Transmission electron microscopy (TEM) has been employed to characterize the size, shape, and morphology of synthesized silver nanoparticles. The TEM image of silver nanoparticles shows the polydispersed nature of particles which is shown in Figures 5(a) and 5(b). From the image, it is evident that the morphology of silver nanoparticles is spherical which is in agreement with the shape of SPR band in the UV-VIS spectrum [30]. The minimum particles size measured from the TEM image is $5.06 \mathrm{~nm}$ which is in good agreement with the particle size calculated from XRD analysis [31].

Toxicology study has been employed to study the toxic effect of these heavy metals as nanoparticles. The same 100 gram soil was used for this study in duplicate result. Earthworms of common Indian species Lumbricus terrestris were 


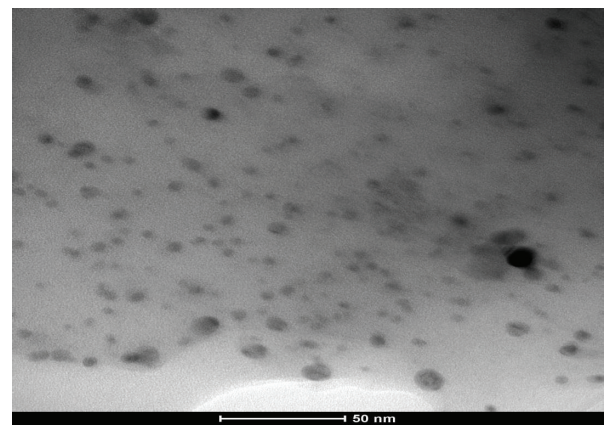

(a)

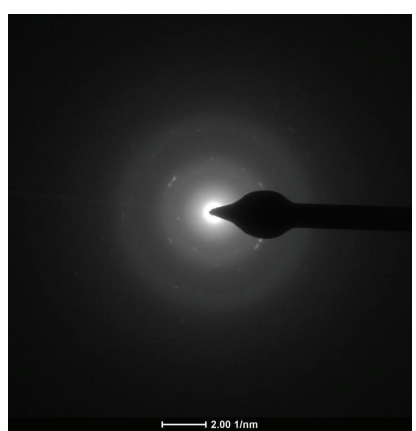

(b)

FIGURE 5: (a) TEM picture of silver nanoparticles synthesized by Triticum aestivum extract. (b) ED image reveals that the silver nanoparticles have polycrystalline structure.

used for this study. Various concentrations were added to the pot where earthworms were kept. Earthworms are stable up to $1500 \mathrm{ppm}$ in pot and for almost a year. The future plan is to extract silver from them so that accumulation can be calculated. So from this experiment, it is shown that earthworms are in good condition till $1500 \mathrm{ppm}$ concentration of silver nanoparticles in normal soil.

\section{Conclusion}

In this paper, we report a green approach for the synthesis of Ag nanoparticles using Triticum aestivum extract. This is a simple, green, and efficient method to synthesize silver nanoparticles at room temperature without using any harmful reducing agents such as sodium borohydride and any capping or dispersing agent. It was concluded that the green synthesized silver nanoparticles were composed of polydispersed spherical particles which were highly crystalline. The particles' size is less than $10 \mathrm{~nm}$ and hydrogen peroxide catalytic activity shows nanoparticle stability till $200 \mu \mathrm{L}$ concentration. Earthworms remain stable till 1500 ppm concentration of silver nanoparticles.

\section{Acknowledgment}

The authors are thankful to the University Grants Commission of India, for their financial support during this work as a UGC-minor research project funding UGC (WRO) Sanction Letter no. F.47-1569/10(WRO) dt 5th October 2010-2012.

\section{References}

[1] M. Mazur, "Electrochemically prepared silver nanoflakes and nanowires," Electrochemistry Communications, vol. 6, no. 4, pp. 400-403, 2004.

[2] N. Rastakhiz, H. Beitollahi, A. Kariminik, and F. Karimi, "Voltammetric determination of carbidopa in the presence of uric acid and folic acid using a modified carbon nanotube paste electrode," Journal of Molecular Liquids, vol. 172, pp. 66-70, 2012.

[3] H. Yaghoubian, H. Karimi-Maleh, M. A. Khalilzadeh, and F. Karimi, "Electrocatalytic oxidation of levodopa at a ferrocene modified carbon nanotube paste electrode," International Journal of Electrochemical Science, vol. 4, no. 7, pp. 993-1003, 2009.

[4] M. Asnaashariisfahani, H. Karimi-maleh, H. Ahmar et al., "Novel 8, 9-dihydroxy-7-methyl-12H-benzothiazolo[2, 3$b$ ]quinazolin-12-one multiwalled carbon nanotubes paste electrode for simultaneous determination of ascorbic acid, acetaminophen and tryptophan," Analytical Methods, vol. 4, pp. 32753282, 2012.

[5] H. Karimi-Maleh, M. A. Khalilzadeh, Z. Ranjbarha, H. Beitollahi, A. A. Ensafi, and D. Zareyee, " $p$-Chloranil modified carbon nanotubes paste electrode as a voltammetric sensor for the simultaneous determination of methyldopa and uric acid," Analytical Methods, vol. 4, pp. 2088-2094, 2012.

[6] A. A. Ensafi, M. Ghiaci, M. Arshadi, and H. Karimi-Maleh, "Synthesis and characterization of ferrocenecarboxaldehyde immobilized on modified $\mathrm{SiO}_{2}-\mathrm{Al}_{2} \mathrm{O}_{3}$ in nanoscale, application for determination of penicillamine," Journal of Nanoparticle Research, vol. 15, p. 1610, 2013.

[7] M. Baghayeri, M. Namadchian, H. Karimi-Maleh, and H. Beitollahi, "Determination of nifedipine using nanostructured electrochemical sensor based on simple synthesis of Ag nanoparticles at the surface of glassy carbon electrode: application to the analysis of some real samples," Journal of Electroanalytical Chemistry, vol. 697, pp. 53-59, 2013.

[8] A. A. Ensafi and H. Karimi-Maleh, "Modified multiwall carbon nanotubes paste electrode as a sensor for simultaneous determination of 6-thioguanine and folic acid using ferrocenedicarboxylic acid as a mediator," Journal of Electroanalytical Chemistry, vol. 640, no. 1-2, pp. 75-83, 2010.

[9] E. Afsharmanesh, H. Karimi-Maleh, A. Pahlavan, and J. Vahedi, "Electrochemical behavior of morphine at $\mathrm{ZnO} / \mathrm{CNT}$ nanocomposite room temperature ionic liquid modified carbon paste electrode and its determination in real samples," Journal of Molecular Liquids, vol. 181, pp. 8-13, 2013.

[10] A. A. Ensafi, H. Bahrami, B. Rezaei, and H. Karimi-Maleh, "Application of ionic liquid- $\mathrm{TiO}_{2}$ nanoparticle modified carbon paste electrode for the voltammetric determination of benserazide in biological samples," Materials Science and Engineering C, vol. 33, no. 2, pp. 831-835, 2013.

[11] A. A. Ensafi, H. Karimi-Maleh, M. Ghiaci, and M. Arshadi, "Characterization of Mn-nanoparticles decorated organo-functionalized $\mathrm{SiO}_{2}-\mathrm{Al}_{2} \mathrm{O}_{3}$ mixed-oxide as a novel electrochemical sensor: application for the voltammetric determination of captopril," Journal of Materials Chemistry, vol. 21, no. 38, pp. 1502215030, 2011. 
[12] A. A. Ensafi, H. Karimi-Maleh, S. Mallakpour, and M. Hatami, "Simultaneous determination of $N$-acetylcysteine and acetaminophen by voltammetric method using $N$-(3,4-dihydroxyphenethyl)-3,5-dinitrobenzamide modified multiwall carbon nanotubes paste electrode," Sensors and Actuators B, vol. 155, no. 2, pp. 464-472, 2011.

[13] T. Tavana, M. A. Khalilzadeh, H. Karimi-Maleh, A. A. Ensafi, H. Beitollahi, and D. Zareyee, "Sensitive voltammetric determination of epinephrine in the presence of acetaminophen at a novel ionic liquid modified carbon nanotubes paste electrode," Journal of Molecular Liquids, vol. 168, pp. 69-74, 2012.

[14] S. Salmanpour, T. Tavana, A. Pahlavan et al., "Voltammetric determination of norepinephrine in the presence of acetaminophen using a novel ionic liquid/multiwall carbon nanotubes paste electrode," Materials Science and Engineering C, vol. 32, no. 7, pp. 1912-1918, 2012.

[15] S. S. Shankar, A. Rai, A. Ahmad, and M. Sastry, "Rapid synthesis of $\mathrm{Au}, \mathrm{Ag}$, and bimetallic Au core-Ag shell nanoparticles using Neem (Azadirachta indica) leaf broth," Journal of Colloid and Interface Science, vol. 275, no. 2, pp. 496-502, 2004.

[16] A.-T. Le, L. T. Tam, P. D. Tam et al., "Synthesis of oleic acidstabilized silver nanoparticles and analysis of their antibacterial activity," Materials Science and Engineering C, vol. 30, no. 6, pp. 910-916, 2010.

[17] M. N. Nadagouda, T. F. Speth, and R. S. Varma, "Microwaveassisted green synthesis of silver nanostructures," Accounts of Chemical Research, vol. 44, no. 7, pp. 469-478, 2011.

[18] O. Y. Golubevaa, O. V. Shamova, D. S. Orlov, T. Y. Pazina, A. S. Boldina, and V. N. Kokryakov, "Study of antimicrobial and hemolytic activities of silver nanoparticles prepared by chemical reduction," Glass Physics and Chemistry, vol. 36, no. 5, pp. 628-634, 2010.

[19] M. Harada, C. Kawasaki, K. Saijo, M. Demizu, and Y. Kimura, "Photochemical synthesis of silver particles using water-inionic liquid microemulsions in high-pressure $\mathrm{CO}_{2}$," Journal of Colloid and Interface Science, vol. 343, no. 2, pp. 537-545, 2010.

[20] K. Li and F.-S. Zhang, "A novel approach for preparing silver nanoparticles under electron beam irradiation," Journal of Nanoparticle Research, vol. 12, no. 4, pp. 1423-1428, 2010.

[21] J. Zhu, S. Liu, O. Palchik, Y. Koltypin, and A. Gedanken, "Shapecontrolled synthesis of silver nanoparticles by pulse sonoelectrochemical methods," Langmuir, vol. 16, no. 16, pp. 6396-6399, 2000.

[22] K. Bhayani, J. M. Rajwade, and K. M. Paknikar, "Radio frequency induced hyperthermia mediated by dextran stabilized LSMO nanoparticles-in vitro evaluation of heat shock protein response," Nanotechnology, vol. 24, Article ID 015102, 2013.

[23] R. Umrani and K. M. Paknikar, "Zinc oxide nanoparticles show anti-diabetic activity in streptozotocin induced type 1 and type 2 diabetic rats," Nanomedicine, 2013.

[24] S. S. Shankar, A. Ahmad, and M. Sastry, "Geranium leaf assisted biosynthesis of silver nanoparticles," Biotechnology Progress, vol. 19, no. 6, pp. 1627-1631, 2003.

[25] J. D. Oei, W. W. Zhao, L. Chu et al., "Antimicrobial acrylic materials with in situ generated silver nanoparticles," Journal of Biomedical Materials Research B, vol. 100, no. 2, pp. 409-415, 2012.

[26] B. S. Atiyeh, M. Costagliola, S. N. Hayek, and S. A. Dibo, "Effect of silver on burn wound infection control and healing: review of the literature," Burns, vol. 33, no. 2, pp. 139-148, 2007.

[27] N. Mude, A. Ingle, A. Gade, and M. Rai, "Synthesis of silver nanoparticles using callus extract of Carica papaya-a first report," Journal of Plant Biochemistry and Biotechnology, vol. 18, no. 1, pp. 83-86, 2009.

[28] S. P. Chandran, M. Chaudhary, R. Pasricha, A. Ahmad, and M. Sastry, "Synthesis of gold nanotriangles and silver nanoparticles using Aloe vera plant extract," Biotechnology Progress, vol. 22, no. 2, pp. 577-583, 2006.

[29] J. Huang, Q. Li, D. Sun et al., "Biosynthesis of silver and gold nanoparticles by novel sundried Cinnamomum camphora leaf," Nanotechnology, vol. 18, no. 10, Article ID 105104, 2007.

[30] P. Kouvaris, A. Delimitis, V. Zaspalis, D. Papadopoulos, S. A. Tsipas, and N. Michailidis, "Green synthesis and characterization of silver nanoparticles produced using Arbutus Unedo leaf extract," Materials Letters, vol. 76, pp. 18-20, 2012.

[31] D. Lee, R. E. Cohen, and M. F. Rubner, "Antibacterial properties of Ag nanoparticle loaded multilayers and formation of magnetically directed antibacterial microparticles," Langmuir, vol. 21, no. 21, pp. 9651-9659, 2005. 

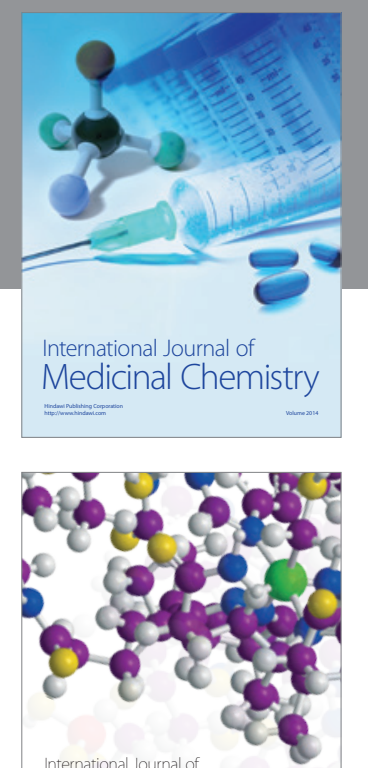

\section{Carbohydrate} Chemistry

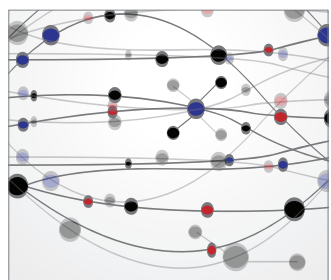

The Scientific World Journal
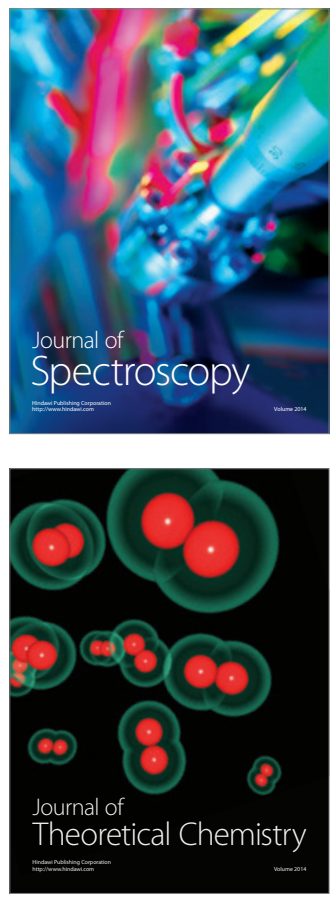
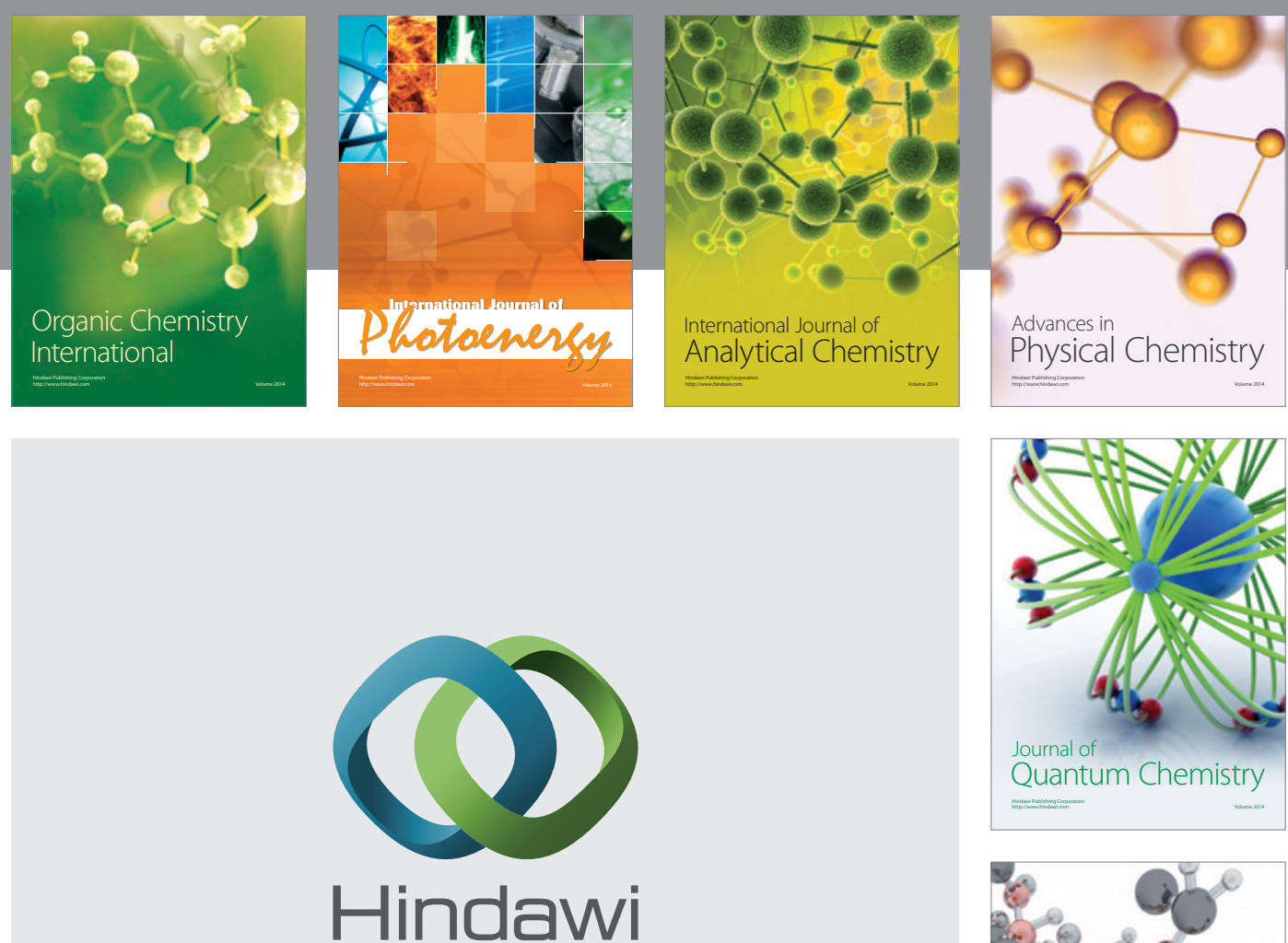

Submit your manuscripts at

http://www.hindawi.com

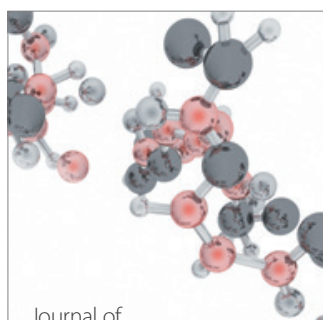

Analytical Methods

in Chemistry

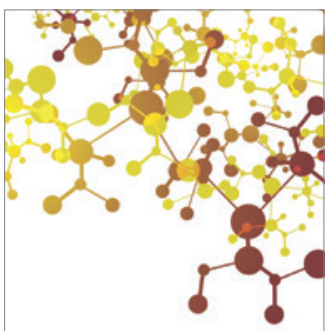

Journal of

Applied Chemistry

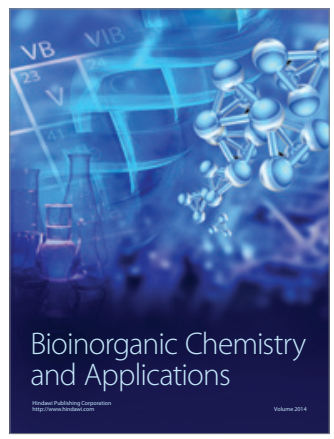

Inorganic Chemistry
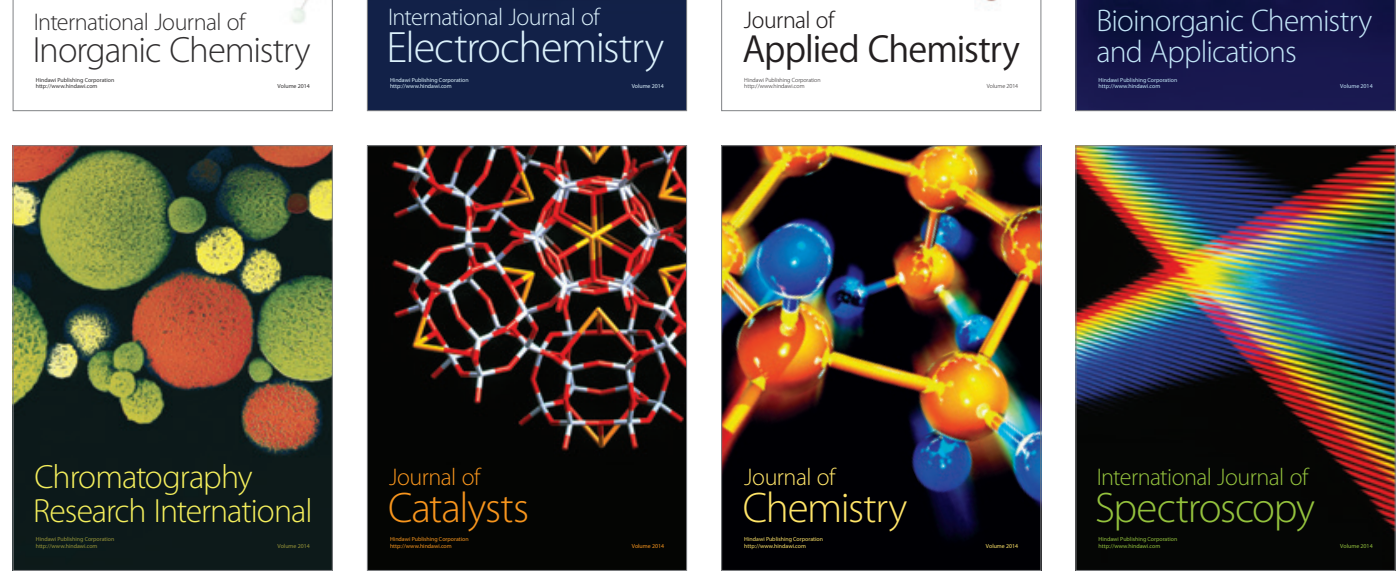